\title{
In memory of Colin Bibby
}

Colin Bibby was a truly remarkable man. He had a life-long interest in almost all things biological and applied scientific thinking and rigour to a vast array of situations, be they the study of a particular conservation problem, or matters concerning the management of an organisation.

When Colin joined the staff of the International Council for Bird Preservation (BirdLife International's predecessor) he set about applying his skills and experience, honed in the UK, to a global conservation network, dynamically promoting research and survey work, priority-setting and target-driven programmes of conservation action for species, sites and habitats. He vigorously championed the free distribution of information, believing passionately that this was the key to successful advocacy. Colin strongly fostered the idea of the 'Biodiversity Commons' as the best way of sharing our knowledge of life on earth in order to ensure its survival. Colin strived to build close and robust working relationships with companies whose activities, by their very nature, resulted in an environmental impact. He engaged with them constructively (and encouraged others to do so too), to develop and implement biodiversity strategies and to set high environmental standards that the corporate sector would adhere to.

The BirdLife International Partnership has much to thank Colin for. He played a major role in helping to shape the organisation's first Strategy and set of Regional Programmes, always promoting science-based advocacy and field action. Colin leaves a great legacy of knowledge and ideas and this publication pays tribute to his innovative approach to the application of ornithology to conservation.

Mike Rands

BirdLife International

June 2008 